\title{
RESPONSABILIDADE SOCIOAMBIENTAL: UMA ANÁLISE DO PROJETO “CAMPUS VERDE - GESTÃO AMBIENTAL DO IFRN"
}

\author{
R. G. LOPES E L. R. MOURA* \\ Instituto Federal de Educação, Ciência e Tecnologia do Rio Grande do Norte - IFRN \\ laysce.moura@ifrn.edu.br*
}

Artigo submetido em novembro/2014 e aceito em junho/2015

DOI: 10.15628/holos.2015.2596

\section{RESUMO}

O artigo analisa a importância da adoção de práticas de responsabilidade socioambiental em organizações públicas, tendo em vista o alcance do desenvolvimento sustentável. Em particular, o artigo foca no Projeto "Campus Verde - Gestão Ambiental do IFRN", apontando benefícios e perspectivas na sua adoção, bem como dificuldades e limitações. O projeto é uma iniciativa do Instituto Federal de Educação, Ciência e Tecnologia do Rio Grande do Norte (IFRN) que busca adotar ações no âmbito da responsabilidade socioambiental em busca do desenvolvimento sustentável. Metodologicamente, tem uma abordagem qualitativa de cunho exploratório e descritivo e para coleta de dados realizou entrevistas com os coordenadores do projeto do campus Natal-Central.
Observou-se que o projeto possibilitou mudanças na instituição que perpassam os eixos temáticos: uso racional dos recursos naturais, gestão adequada dos resíduos sólidos, licitação sustentável, saúde e qualidade de vida e formação continuada em educação ambiental. É um projeto com perspectivas promissoras, no entanto ainda precisa se estruturar de modo a contemplar a unificação das ações e a sistematização dos processos, passando por sua institucionalização. Destarte, pode-se considerar que a atitude adotada pelo o IFRN se mostra positiva, pois traz uma nova forma de pensar e atuar das organizações públicas voltada para a responsabilidade socioambiental e o respeito ao tripé da sustentabilidade: social, ambiental e econômico.

PALAVRAS-CHAVE: desenvolvimento sustentável, responsabilidade socioambiental, A3P.

\section{SOCIOENVIRONMENTAL RESPONSIBILITY: AN ANALYSIS OF THE PROJECT "CAMPUS VERDE - GESTÃO AMBIENTAL DO IFRN"}

\begin{abstract}
The article analyzes the importance of adopting environmental responsibility practices in public organizations to achieve sustainable development. In particular, the article focuses on the Project "Campus Verde-Gestão Ambiental do IFRN" pointing benefits and prospects for its adoption, as well as difficulties and limitations. The project is an initiative of the Federal Institute of Education, Science and Technology of Rio Grande do Norte (IFRN). Methodologically, it has a qualitative approach and an exploratory and descriptive nature and for data collection interviews were used. It was observed that the project possible changes in the
\end{abstract}

institution that underlie the themes: rational use of natural resources, solid waste management, sustainable government acquisition, health and quality of life and continued training in environmental education. It is a project with good prospects, however need to improve the structure providing unified actions and systematized processes, through its institutionalization. Thus, it can be considered that the attitude adopted by IFRN shows up positive as it brings a new way of thinking and acting of public organizations focused on socioenvironmental responsibility and on the respect of the triple bottom line: social, environmental and economic.

KEYWORDS: sustainable development, socioenvironmental responsibility, A3P. 


\section{INTRODUÇÃO}

O período que se estende dos anos 1960 aos anos 1990, segundo Scotto, Carvalho e Guimarães (2007), foi marcado por momentos de discussões que colocavam em pauta a relação desenvolvimento e progresso com responsabilidade social e ambiental. Foi a partir desses debates, que os indivíduos passaram a enxergar os problemas de sustentabilidade que pairavam sobre a sociedade. Nesse sentido, era necessário que os empresários e os indivíduos adotassem uma nova postura, baseado em ações que visassem não somente os lucros, mas que tivessem um olhar mais sistêmico, envolvendo assim a sociedade e todos os seus atores sociais.

Dentro dessa perspectiva, surgem definições que abordam a responsabilidade social como sendo, relacionada "[...] à boa governança da organização, a uma gestão ética e sustentável e ao conjunto dos compromissos voluntários que uma organização assume para administrar seus impactos sociais, ambientais e econômicos que produz na sociedade" (DIAS, 2012, p. 06). Logo, coloca-se em questão a atuação das organizações e dos indivíduos, dos quais devem focar a relação crescimento e desenvolvimento sustentável buscando ter um comportamento ético e ecologicamente responsável.

Com a evolução das discussões em torno de sustentabilidade, na década de 1990 há um novo direcionamento do entendimento de responsabilidade social e uma ampliação da percepção que deveria ser uma preocupação das organizações de uma forma geral quer seja privada, pública e terceiro setor. Assim, o conceito agrega o termo ambiental e passa a ser discutido em todos os setores da sociedade como algo a ser praticado por todas as instituições.

Ao longo das últimas décadas, o que se observa é uma convergência e entrelaçamento desses conceitos, pois a responsabilidade socioambiental das organizações (dimensão micro) contribui para o desenvolvimento sustentável (dimensão macro). Então, a inserção da temática de sustentabilidade nas organizações é fundamental para que possamos construir uma sociedade equilibrada e sustentável.

Diante disso, é importante que as organizações públicas também estejam alinhadas com esses conceitos no exercício da sua função social. Para tanto, foi criado pelo governo federal uma cartilha denominada Agenda Ambiental na Administração Pública (A3P) para incentivar práticas e ações de responsabilidade socioambiental em instituições públicas (MMA, 2009).

Nesse sentido, a presente pesquisa buscou analisar o Projeto Campus Verde - "Gestão Ambiental do IFRN", apontando benefícios e perspectivas na sua adoção, bem como dificuldades e limitações. O projeto é uma iniciativa do Instituto Federal de Educação, Ciência e Tecnologia do Rio Grande do Norte (IFRN) que busca adotar em cada Campus ações no âmbito da responsabilidade socioambiental em busca do desenvolvimento sustentável.

Para tanto, o presente artigo aborda no seu referencial teórico os conceitos sobre desenvolvimento sustentável e responsabilidade socioambiental e apresenta as principais ideias sobre a Agenda Ambiental na Administração Pública. Em seguida faz o delineamento da pesquisa, apontando os passos e os caminhos percorridos. Após a explanação das etapas, expõe-se o projeto Campus Verde, perpassando os pontos: comissões e eixos temáticos, ações e atividades desenvolvidas, agenda ambiental na administração pública e as mudanças, seus limites e suas 
possibilidades. Por fim, tece-se as considerações finais, apresentando os benefícios e as perspectivas, bem como algumas sugestões para melhorias do projeto e para futuras pesquisas.

\section{DESENVOLVIMENTO SUSTENTÁVEL}

As discussões sobre sustentabilidade têm início nos anos 60 do século $X X$, porém é na década de 1970 que a temática ganha relevância mundial quando a Organização das Nações Unidas (ONU) propõe discutir sobre meio ambiente e modelo de desenvolvimento nas conferências internacionais. Além disso, os problemas em relação ao crescimento desenfreado são fundamentados por um estudo realizado por cientistas e técnicos do Massachussetts Institute of Technology (MIT) que ficou conhecido como Relatório Meadows. (SCOTTO; CARVALHO; GUIMARÃES, 2007).

Em 1972, a Conferência de Estocolmo forma uma comissão para construir um relatório sobre meio ambiente e desenvolvimento. O resultado foi o documento Nosso futuro comum também conhecido como Relatório Brundtland. Nele há um diagnóstico e ações que devem ser adotadas por todos os países. Além disso, é apresentada a definição que até hoje permeia o entendimento de desenvolvimento sustentável como a possibilidade da sociedade suprir as demandas presentes sem prejudicar as demandas das gerações futuras. Em 1992, o desdobramento disso resultou na Eco 92 que fortaleceu as discussões no Brasil e no mundo sobre a temática (SCOTTO; CARVALHO; GUIMARÃES, 2007). Em 2012, ocorreu a Rio +20 que teve o objetivo de reafirmar o compromisso com o desenvolvimento sustentável no âmbito mundial, verificando os avanços, as falhas e as novas propostas de atuação.

O conceito se fundamenta principalmente nas questões relacionadas ao desenvolvimento "insustentável", frente a uma sociedade fortemente marcada pelo capitalismo, consumo desenfreado e pela lógica da acumulação. O ideal de progresso e desenvolvimento rápido propagado pelo modelo capitalista leva essa sociedade a assumir posturas, por vezes, de forma irresponsável, fazendo uso dos recursos naturais de forma descontrolada e tendo como consequência direta crises ambientais e sociais.

Assim, é imperativo que a sociedade adote uma nova postura voltada, principalmente, para utilização eficiente dos recursos com o objetivo de evitar desperdícios e uso inadequado dos mesmos. Um dos principais desafios enfrentados para que isso ocorra é promover uma educação voltada para transformação dos pensamentos e das atitudes, ou seja, uma modificação no comportamento individual que englobe o consumo, a reutilização e a reciclagem.

A realização de ações como essas produziriam consequências positivas e uma significativa redução dos impactos ambientais e sociais. Além disso, ao adotar tais atitudes os cidadãos estariam considerando toda a coletividade, visto que a partir de ações individuais proporcionariam à sociedade um mundo mais sustentável. Portanto, o indivíduo tem um papel fundamental nesse processo quer seja na compra de produtos 'ecologicamente corretos' ou na aquisição apenas do que seja necessário. "As opções do indivíduo consciente incluiriam reavaliação da quantidade de produtos adquiridos e de suas marcas em função de sua responsabilidade social, redução do desperdício e reaproveitamento ou reciclagem." (COSTA; TEODÓSIO, 2011, p. 120).

Cabe enfatizar que para a efetivação das mudanças as ações devem partir tanto dos cidadãos individualmente quanto da coletividade, quer seja formalmente organizada ou não. Tem 
que englobar também as empresas que precisam se preocupar com todo o ciclo produtivo e os seus stakeholders e o Estado com seu papel regulador e formulador de políticas públicas que promovam ações e programas que estimulem essa conscientização e mudança de comportamento.

\section{RESPONSABILIDADE SOCIOAMBIENTAL}

Os estudos sobre responsabilidade social surgiram no âmbito das empresas em torno de 1950. O evento que favoreceu o aparecimento da temática foi a Grande Depressão Americana em 1930. No primeiro momento o conceito era permeado por uma visão paternalista e assistencialista que era exercida pelo empresário, porém ao longo do tempo houve uma evolução do conceito e ampliação do entendimento. Nesta segunda ocasião o termo passa a ser compreendido como a responsabilidade que as empresas tinham de nas suas ações levarem em consideração as questões econômicas, sociais e ambientais (MOURA, 2010).

Com o desenvolvimento das discussões em torno de sustentabilidade, na década de 1990 há um novo direcionamento do entendimento de responsabilidade social e uma ampliação da percepção que deveria ser uma preocupação das organizações de uma forma geral quer seja privada, pública e terceiro setor. Assim, o conceito agrega o termo ambiental e passa a ser discutido em todos os setores da sociedade como algo a ser praticado por todas as instituições.

Apesar da crescente importância do tema observada nos últimos anos, a noção de responsabilidade social não é nova e, desde os anos 80 , faz parte de uma agenda voluntária do setor empresarial relacionada ao desenvolvimento de projetos e ações de cunho social. A partir de 1990, o número de iniciativas e as discussões relacionadas ao tema se expandiram e atualmente - como mencionado anteriormente - $\mathrm{o}$ assunto faz parte da agenda internacional, não apenas restrita ao setor empresarial, mas também no âmbito das instituições governamentais que, cada vez mais, têm participado como ator do processo, inclusive criando estruturas de governo específicas para tratar do tema (MMA, 2009, p. 21).

Atualmente, o conceito pode ser compreendido como a responsabilidade que as organizações têm com os resultados de suas ações nos âmbitos econômicos, sociais e ambientais fundamentadas no comportamento ético e transparente. De acordo com a ISO 26000 (ABNT, 2010, p. 04 - grifo no original):

Responsabilidade de uma organização pelos impactos de suas decisões e atividades na sociedade e no meio ambiente, por meio de um comportamento ético e transparente que

- contribua para o desenvolvimento sustentável, inclusive a saúde e bem-estar da sociedade;

- leve em consideração as expectativas das partes interessadas;

- $\quad$ esteja em conformidade com a legislação aplicável e seja consistente com as normas internacionais de comportamento; e

- esteja integrada em toda a organização e seja praticada em suas relações.

Dois pontos podem ser destacados: a amplitude do conceito e a relação com o desenvolvimento sustentável. Assim sendo, para que a organização seja considerada como responsável socialmente ela deverá não apenas adotar práticas e ações pontuais que estejam 
relacionadas ao tema, mas sim deve inserir na sua cultura organizacional. Ou seja, a responsabilidade socioambiental deve fazer parte de todas as suas atividades.

Além disso, deve estar alinhada com o desenvolvimento sustentável fortalecendo a ideia de que a responsabilidade socioambiental é um desdobramento do desenvolvimento sustentável. Assim, pode-se dizer que no nível organizacional e individual as organizações devem ser responsáveis socioambientalmente para que se possa alcançar o desenvolvimento sustentável.

Assim, tanto para as organizações privadas quanto para públicas o compromisso perante a sociedade é o mesmo, uma vez que, devem desenvolver ações e projetos que atendam as demandas e necessidades de todos. Através de ações, que, segundo Domingos (2008), englobem o mesmo cuidado tanto com o público interno e quanto com o público externo.

\title{
4 AGENDA AMBIENTAL NA ADMINISTRAÇÃO PÚBLICA - A3P
}

A Agenda Ambiental na Administração Pública refere-se a uma agenda que busca implantar novas práticas e ações dentro das instituições públicas, todas elas voltadas ao viés da responsabilidade socioambiental. Assim, a A3P se caracteriza como:

\begin{abstract}
Um programa que busca incorporar os princípios da responsabilidade socioambiental nas atividades da Administração Pública, através do estímulo a determinadas ações que vão, desde uma mudança nos investimentos, compras e contratações de serviços pelo governo, passando pela sensibilização e capacitação dos servidores, pela gestão adequada dos recursos naturais utilizados e resíduos gerados, até a promoção da melhoria da qualidade de vida no ambiente de trabalho. (MMA, 2009, p.32)
\end{abstract}

Observa-se que A3P é uma agenda que busca trabalhar em consonância aos princípios constitucionais como da economicidade, eficiência, eficácia, procurando assim, servir com presteza e zelo a sociedade e o meio ambiente.

O programa foi desenvolvido tendo como base cinco eixos temáticos que buscam a reflexão e a mudança de atitude no dia a dia das rotinas e atividades das instituições, a saber: uso racional dos recursos naturais e bens públicos, gestão adequada dos resíduos gerados, qualidade de vida no ambiente do trabalho, sensibilização e capacitação dos servidores e licitações sustentáveis (MMA, 2009).

O uso racional dos recurso naturais e bens públicos é o eixo que trabalha a conscientização das pessoas em relação ao desperdício, ou seja, busca refletir sobre as mudanças de atitudes que podem acarretar a diminuição do uso da energia, da água e da madeira, bem como dos materiais e bens utilizados na organização, tais como o papel e os copos plásticos.

A gestão adequada dos resíduos gerados é o eixo que busca a reflexão em relação à redução do consumo por meio da política dos 5R's - repensar, reduzir, reutilizar, reciclar e recusar - e a destinação correta dos resíduos gerados. Para tanto, esclarece os códigos de cores estabelecidos para os diferentes tipos de resíduos (Resolução CONAMA no275/01) e institui a coleta seletiva solidária (Decreto no 5.940/06).

A qualidade de vida no ambiente do trabalho é o eixo que procura promover um ambiente de trabalho que permita o desenvolvimento pessoal e profissional. Dessa forma, busca alinhar os 
objetivos organizacionais com os individuais. Parte do princípio que um trabalhador satisfeito é mais produtivo. Assim, estabelece que as instituições públicas precisam desenvolver e implantar programas voltados para "o grau de satisfação da pessoa com o ambiente de trabalho, melhoramento das condições ambientais gerais, promoção da saúde e segurança, integração social e desenvolvimento das capacidades humanas, entre outros fatores." (MMA, 2009, p. 43).

Sensibilização e capacitação dos servidores é o eixo que trabalha a conscientização dos servidores, bem como o desenvolvimento de competências institucionais e individuais. Dessa forma, o que se busca é uma mudança de atitudes das pessoas promovida por uma nova compreensão das questões socioambientais e do conhecimento adquirido pela capacitação melhorando seu desempenho nas atividades institucionais.

Licitações sustentáveis é o eixo que intenta trazer uma nova postura nas compras governamentais e promover a responsabilidade socioambiental. Diante disso, busca-se adquirir produtos e serviços sustentáveis que tanto favorece " a conservação do meio ambiente mas também apresentam uma melhor relação custo/benefício a médio ou longo prazo quando comparadas às que se valem do critério de menor preço." (MMA, 2009, p. 47).

Portanto, a A3P é um programa amplo que busca inserir nas instituições ações voltadas para a responsabilidade socioambiental numa perspectiva mais profunda, pois se preocupa não apenas com a racionalização dos recursos, mas também com as pessoas que fazem parte da instituição. Nesse sentido, o objetivo é promover uma nova postura que esteja alinhada com os valores da sustentabilidade.

\section{DELINEAMENTO DA PESQUISA}

A presente pesquisa tem uma abordagem qualitativa de cunho exploratório e descritivo e utilizou como estratégia o estudo de caso que "investiga um fenômeno contemporâneo (o 'caso') em profundidade e em seu contexto de mundo real" (YIN, 2015, p. 17). Para tanto, teve como objeto de análise o Projeto Campus Verde no IFRN - Campus Natal Central.

O Projeto abrange toda a instituição, porém cada campus tem uma comissão própria que é responsável pelo funcionamento e planejamento das atividades e projetos a serem realizados no campus. Porém, todas essas comissões são coordenadas pela presidente geral do projeto.

Para coleta de dados, foram realizadas entrevistas no período que se estende de dezembro de 2013 a janeiro de 2014 com os principais responsáveis do Projeto Campus Verde no IFRN Campus Natal Central que é a iniciativa que tem como um dos objetivos implantar a A3P. No total foram entrevistadas seis pessoas: a gestora principal e cinco coordenadores dos eixos temáticos (uso racional dos recursos naturais, gestão adequada dos resíduos sólidos, licitação sustentável, saúde e qualidade de vida e formação continuada em educação ambiental) da comissão Campus Natal - Central.

Nas entrevistas buscou-se obter informações relevantes à pesquisa como, por exemplo, como tem sido feita a implantação do projeto, se existe acompanhamento e avaliação do mesmo, entre outros pontos relevantes. Portanto, a abrangência da pesquisa se limitou a visão dos gestores sobre o projeto supracitado. 


\section{PROJETO CAMPUS VERDE}

Desde 2011, no IFRN está sendo implantado o Projeto Campus Verde que é uma iniciativa que tem como um dos objetivos específicos implantar a A3P no Campus Natal-Central. No momento da pesquisa a instituição estava no processo de adesão ao programa e a documentação requerida estava no Ministério do Meio Ambiente (MMA) para análise. Além disso, uma técnica do referido órgão estava acompanhando e orientando os passos necessários para a implantação. Apesar de ainda está em tramitação, muitas ações estão sendo realizadas tendo como foco a responsabilidade socioambiental e o desenvolvimento sustentável.

O projeto, segundo a principal coordenadora, iniciou-se com pequenas e pontuais ações que visavam principalmente a coleta seletiva, tendo como objetivo instalar essa atividade na Reitoria e posteriormente expandir para os demais campi. No entanto, no decorrer do processo surgiram críticas que questionavam a ideia de sustentabilidade restrita a coleta seletiva.

O conceito de desenvolvimento sustentável é amplo e engloba não apenas a questão ambiental, mas envolve questões sociais e econômicas, sendo essas ainda associadas ao princípio de justiça social, assim como afirma Scotto, Carvalho e Guimarães (2007). Logo, verifica-se que esse entendimento é bem mais amplo do que se estava realizando na instituição. As ações não poderiam apenas partir de uma atividade, mas também contemplar a qualidade de vida do servidor, a economia, a política, a sociedade e o meio ambiente. Além disso, as atividades devem englobar também o conceito de responsabilidade socioambiental, ou seja, o compromisso institucional de implantar ações que reportem a boa governança e a responsabilização dos impactos das atividades desenvolvidas.

Outro ponto relevante relatado pelos coordenadores entrevistados, refere-se a necessidade de um processo de institucionalização e sistematização do projeto. A sistematização envolvendo a padronização das ações e as trocas de informações entre os campi, possibilitando assim que haja uniformidade entre todas as unidades e estas trabalhem com as mesmas programações, cronogramas e objetivos.

Quanto a institucionalização, é necessário a criação de um documento formal que dê respaldo ao projeto, para que, de fato os stakeholders possam desempenhar as atividades. Pois, atualmente a comissão conta com a discricionariedade dos diretores e servidores de cada campus.

Outro ponto crítico relatado pela coordenadora geral e pelo coordenador do eixo temático 'uso racional dos recursos naturais', refere-se à forma com que se iniciou o projeto, pois não foi feito um diagnóstico da situação da instituição que apontasse os principais gargalos das questões que tratam a A3P. O que se aplicavam eram pequenas práticas em determinados pontos considerados problemáticos. Além disso, as atividades desenvolvidas estavam indo de encontro ao que era criticado por Moura (2010) do qual discutia a necessidade da conscientização e que não é suficiente adotar práticas superficiais e ações filantrópicas, pois a abrangência da responsabilidade social é bem mais ampla.

A seguir será explicitado o Projeto Campus Verde em relação às suas comissões e eixos temáticos, as ações e atividades desenvolvidas, a vinculação com a Agenda Ambiental na Administração Pública e, por fim, as mudanças promovidas, seus limites e suas possibilidades. 


\subsection{Comissões e Eixos Temáticos}

As comissões do projeto Campus Verde são definidas através de portaria emitida pelo Diretor-Geral de cada campus e encontram-se divididas por eixos temáticos - Uso racional dos Recursos Naturais, Gestão adequada dos Resíduos Sólidos, Licitação Sustentável, Saúde e Qualidade de Vida e Formação continuada em Educação Ambiental. Geralmente, as comissões são mistas formadas por alunos, professores, técnicos e terceirizados; e têm como objetivo, segundo relato dos coordenadores dos eixos temáticos, implantar o projeto da melhor forma possível. Para isso, os membros de cada comissão passam por treinamentos e palestras para que todos possam entender o funcionamento do projeto, a forma de atuar e o significado de cada ação, bem como compreendam como fazer um diagnóstico e criar soluções para os pontos problemáticos.

Nas reuniões cada membro da comissão tem a possibilidade de apresentar suas realidades e possibilitar discussões sobre o tema. Geralmente, esses debates são feitos em torno de pontos chaves - social, econômico, ecológico, especial e cultural - relevantes para o tema da sustentabilidade.

Ainda sobre essas reuniões, geralmente ocorrem, conforme relato pela coordenadora geral, com a periodicidade de três reuniões por ano. Porém não há restrições para que sejam feitas mais do que três reuniões, pois os coordenadores precisam compartilhar e integrar todas as atividades e ações que estão sendo desenvolvidas por cada campus, visto que cada um possui comissão específica.

\subsection{Ações e atividades desenvolvidas}

O Projeto Campus Verde conta com algumas atividades e ações que já estão sendo desenvolvidas e que abarcam as questões relacionadas à responsabilidade socioambiental.

Dentre essas atividades apresenta-se, conforme o coordenador do eixo temático Gestão adequada dos Resíduos Sólidos, o projeto de coleta seletiva, que contempla a separação dos resíduos gerados divididos em lixo seco e lixo molhado. Esta etapa é essencial para o processo de reciclagem, pois a separação feita da maneira correta facilita o manuseio e promove uma melhor qualidade do material coletado.

Além disso, o IFRN desenvolve alguns projetos de extensão e atua no Programa Mulheres Mil que incentivam a reciclagem do material descartado para a confecção de objetos que possam ser usados novamente ou comercializados. Como por exemplo a utilização de papéis e papelões na produção de pequenos jarros, bonecos 'joão teimoso' e chaveiros.

Tem-se também a reutilização de alguns materiais, como por exemplo folhas A4, conforme relatado pelo coordenador, podendo ser utilizadas como papel para rascunho e na criação de blocos de anotação. Tem-se também a utilização de garrafões de água que passam a ser utilizados como lixeira e pequenas caixas de papelão que ficam ao lado das impressoras para coleta de papéis.

Nesse contexto, o campus possui também uma área reservada para o armazenamento dos resíduos aonde todo material coletado é separado e armazenado para que a Cooperativa de Catadores de Materiais Recicláveis da Cidade do Natal/RN (COOPCICLA), que tem parceria como IFRN, possa recolhê-los. Essa cooperativa foi escolhida a partir de Chamada Pública no 01/2013 - 
Processo Seletivo para Coleta Seletiva Solidária dos Resíduos Recicláveis do IFRN - instaurada pela presidente da comissão Campus Verde.

Em consonância com a Instrução Normativa № 10, de 12 de Novembro de 2012, existem também algumas práticas usuais que promovem diferenças, relatado pelo coordenador do eixo temático Licitação Sustentável como, por exemplo, antes de imprimir qualquer arquivo os servidores são orientados a procurar revisá-lo para evitar gasto desnecessário de papel, dar preferência por trâmite de documentos por meio eletrônico e utilizar com mais frequência o Sistema Unificado da Administração Pública (SUAP).

Outras atividades são desenvolvidas, como por exemplo, a coleta de óleo. Da qual, o instituto recolhe esse material, segundo o coordenador de Resíduos Sólidos, e uma parte fica para produção de sabão desenvolvida no Projeto do Programa Mulheres Mil, e o restante é dada uma destinação correta. Observa-se também a coleta de pilhas e baterias, que são feitas através dos ecopontos localizados, segundo a presidente do projeto, em locais estratégicos (ao lado do computador de bater ponto).

Um ação de destaque do Projeto Campus Verde refere-se a substituição de copos descartáveis. De acordo com a presidente geral do projeto são realizadas algumas campanhas de conscientização da importância de se substituir o uso do copo descartável dando prioridade ao uso de canecas, xícaras e garrafas que podem ser lavadas e utilizadas novamente. No IFRN Campus Natal Central foram distribuídas canecas reutilizáveis para os servidores, porém, como relatado pelo coordenador do eixo temático de Resíduos Sólidos, ainda há uma resistência a essa substituição. Portanto, essa é uma ação que ainda deve ser melhor trabalhada.

Além disso, são realizadas atividades que promovam a conscientização quanto ao uso da água e da energia elétrica; preferência de aparelhos e móveis que sejam sustentáveis (compras sustentáveis); utilização de sensores de presença para ativação das lâmpadas e placas de energia solar (fotovoltaicas).

São ações que buscam provocar uma mudança de hábito tendo em vista o desenvolvimento sustentável. É nessa perspectiva que o projeto Campus Verde atua, pois, segundo os coordenadores, ele busca provocar uma mobilização e um maior envolvimento dos stakeholders, contribuindo para a inserção da responsabilidade socioambiental no IFRN e para o alcance do desenvolvimento sustentável.

\subsection{Agenda Ambiental na Administração Pública}

As ações de sustentabilidade e responsabilidade social desenvolvidas pelo projeto Campus Verde visam provocar mudanças positivas no instituto. Segundo a coordenadora do eixo temático Educação Ambiental, as atividades vão desde práticas filantrópicas como doação de roupas e livros até atuações voltadas a sociedade e ao meio ambiente.

Verifica-se que esse projeto engloba as ações previstas na A3P, inclusive os eixos temáticos propostos no projeto seguem o direcionamento dado pelo programa federal. Porém, conforme relatado pela presidente do projeto, aquele não se restringe ao recomendado na $\mathrm{A} 3 \mathrm{P}$ e tem um planejamento mais amplo.

É possível encontrar vários pontos convergentes nas ações previstas na agenda e nas atividades desenvolvidas no Campus Natal-Central, como por exemplo, as ações de redução do 
consumo de energia e copos descartáveis, a adesão a coleta seletiva solidária e o incentivo à reciclagem, os projetos de inserção de sustentabilidade nos processos licitatórios, a instalação de painéis fotovoltaicos, a ampliação dos programas voltados à qualidade de vida e saúde de servidor que contempla a atividade de "[...] ginástica laboral, orientação nutricional, saúde ocupacional, Comissão interna de prevenção de acidentes" (MMA, 2009, p.43)

A comissão do projeto Campus Verde tem sua atuação voltada para realizar o diagnóstico dos pontos críticos para, posteriormente, desenvolver projetos que venham suprir essas falhas e repensar em cima das temáticas propostas. As ações que são desenvolvidas podem se basear em atividades já realizadas por outros órgãos públicos que também aderiram a ao programa da A3P.

Cabe enfatizar que não basta apenas assinar o termo de adesão da agenda, precisa-se de fato seguir suas diretrizes. Conforme destacado pelo coordenador do eixo temático Licitação Sustentável, a instituição ao aderir a agenda ambiental deve buscar criar ferramentas que facilitem o diagnóstico do ambiente, o apontamento dos pontos críticos, as possíveis soluções e ainda que esses instrumentos sejam compartilhados com todos da comissão como forma de facilitar o monitoramento e a avaliação.

O empenho e a colaboração dos stakeholders na construção do projeto é fundamental, pois, como abordado na $\mathrm{A} 3 \mathrm{P}$, as mudanças para que sejam efetivas devem contar com 0 comprometimento individual e coletivo. Além disso, os órgãos públicos, segundo a coordenadora do eixo temático Educação Ambiental, precisam entender que são referência para a sociedade e, por isso, devem agir dentro os preceitos éticos e morais, adotando uma postura que respeitem o tripé da sustentabilidade: social, econômico e ambiental.

\subsection{Mudanças, limites e dificuldades}

O projeto Campus Verde tem apresentado resultados positivos, destacando que é uma avaliação tida com base na percepção dos gestores. Segundo relato da comissão do campus NatalCentral, já é perceptível algumas mudanças no comportamento dos servidores e dos alunos. Principalmente no que se refere a manutenção dos jardins, redução do gasto com água e com copos descartáveis.

Um fator importante é o apoio que o projeto tem recebido dos setores de Comunicação Social e Recursos Humanos, dos quais estão bastante empenhados em divulgar essas ações. Segundo a coordenadora do eixo de Educação Ambiental, são feitas campanhas educativas, com distribuição de panfletos, criação de placas com sinalizações e informativos, distribuição de material de canetas e cadernos com folhas de papel reciclável. Tem-se também ações para melhorar a qualidade de vida do servidor com confraternizações, projetos de desenvolvimento e capacitação e comemoração do aniversariante do mês.

Apesar dos avanços, o projeto apresenta alguns limites que se referem a necessidade de levar essas discussões a respeito do desenvolvimento sustentável e responsabilidade social para as salas de aula, ou seja, incluir nas reuniões e planejamentos pedagógicos, para provocar um visão crítica sobre e despertar o desejo de participação por parte da comunidade. Além disso, verifica-se que ainda não há uma ampla difusão do assunto, visto que, isso requer tempo, interesse e apoio dos gestores, principalmente da alta administração, e dos coordenadores. 
Há também o enfrentamento de dificuldades nesse processo de implantação do projeto. Conforme relatado pela comissão, ainda existe resistência por parte de alguns servidores, que mantém uma visão equivocada, considerando que o que é público tem que ser utilizado, pois é fruto dos impostos e deve sim ser usado. Além disso, o projeto requer um maior envolvimento e apoio da alta administração, pois sem isso o alcance dos seus objetivos será limitado.

\section{CONSIDERAÇÕES FINAIS}

Os conceitos de desenvolvimento sustentável e responsabilidade socioambiental, assim como analisado, surgem em meio a um processo de desenvolvimento e crescimento desordenado, baseado em um sistema de produção e consumo desenfreado. É nesse contexto que surgem as primeiras críticas e perspectivas de mudanças sobre tais posturas.

É inserido nesse ambiente de mudanças que a pesquisa buscou explanar sobre a importância de se adotar políticas de sustentabilidade e responsabilidade socioambiental em instituições públicas com base no projeto Campus Verde - Gestão Ambiental do IFRN, tendo como estudo o campus Natal - Central.

Observou-se que o projeto tem como objetivo adotar políticas de sustentabilidade e responsabilidade socioambiental no campus, a partir de ações que vão desde a coleta seletiva a práticas que visem o bem estar e a saúde dos servidores e alunos. É um projeto com perspectivas promissoras, pois procuram provocar a mobilização e sensibilização de todos para haja engajamento, participação e cooperação em todas as atividades, e ainda procura provocar mudanças de hábitos e comportamentos.

No entanto, é um projeto que ainda precisa passar por um processo de melhor estruturação, pois, de fato ainda falta um diagnóstico mais preciso sobre determinadas áreas, e ainda que sejam desenvolvidos instrumentos para melhor acompanhamento. Sem a comunicação entre os participantes fica difícil unificar as ações. Com isso, para melhor articular e sistematizar o projeto tem-se a divisão da comissão em eixos temáticos que procuram identificar as dificuldades e visualizar perspectivas de áreas chaves. Essa divisão é feita com base na cartilha A3P, e tem um papel essencial no desenvolvimento dessas novas políticas.

Nesse sentido, apresenta-se como sugestão de melhoria para as atividades desenvolvidas pela comissão a seguinte ideia, para que haja um maior empenho por parte dos membros, se faz necessário que seja designado um tempo específico do qual o servidor dedique aquele momento a planejar e desenvolver atividades no âmbito de sua responsabilidade. As atividades pertinentes ao projeto devem fazer parte das atribuições dos membros da comissão sendo, portanto, parte de uma política institucional.

Verificou-se que a adoção de práticas de sustentabilidade no setor público enfrenta diversas dificuldades, seja pela resistência dos servidores ou pela falta de incentivo da própria administração. Por ser algo novo as instituições mantém ainda uma objeção, mas aos pouco vai se ampliando. Como sugestão de melhoria, tem-se que as instituições públicas devem compreender a importância que se tem ao adotar tais medidas. São simples e pequenas ações que podem transformar o ambiente e a sociedade. Assim, é visível que o IFRN não deve deixar de apoiar tais projetos, deve-se ter uma campanha mais ampla de divulgação que possa atingir a todos que ali 
atuam, promovendo treinamentos, palestras, discussões e ainda trazendo exemplo de ações práticas do dia-a-dia que podem gerar mudanças.

Desse modo, infere-se que as instituições públicas devem também ter essa visão, pois são múltiplos os benefícios gerados a partir da adoção desse tipo de política. Consciente que trará contribuição à todos, pois envolve não só a comunidade interna, como também a sociedade, organizações públicas e privadas.

Destarte, pode-se considerar que a atitude adotada pelo o IFRN, mostra-se positiva, pois traz uma nova forma de pensar e atuar das organizações públicas voltada para a responsabilidade socioambiental e o respeito ao tripé da sustentabilidade: social, ambiental e econômico. Dessa forma, cabe ao instituto apoiar e incentivar ainda mais o projeto.

Para finalizar, enfatiza-se a importância de se dar seguimento a essa pesquisa, pois esse projeto ainda se encontra no processo de implantação. Além disso, é importante que se façam pesquisas na área buscando abordar uma visão diferente das relatadas pelos gestores, procurando observar qual a visão que os outros stakeholders têm em relação ao Projeto Campus Verde.

\section{REFERÊNCIAS}

1. ASSOCIAÇÃO BRASILEIRA DE NORMAS TÉCNICAS. NBR 26000: 2010: Diretrizes sobre responsabilidade social. Rio de Janeiro: ABNT, 2010.

2. COSTA, Daniela; TEODÓSIO, Armindo. Desenvolvimento Sustentável, Consumo e Cidadania: um estudo sobre a (des)articulação da comunicação de organizações da sociedade civil, do estado e das empresas. REV. ADM. MACKENZIE. São Paulo - SP: RAM, v.12, n.3, jun. 2011. Disponível em: < http://www.scielo.br/scielo.php?pid=S1678-69712011000300006\&script= sci_arttext >. Acesso em: 26 de junho de 2013.

3. DIAS, Reinaldo. Responsabilidade Social: Fundamentos e Gestão, 1a ed. São Paulo: Atlas, 2012. v.1.

4. DOMINGOS, Maria de Lurdes Costa. Responsabilidade Social no Setor Público. In: Congresso Nacional de Excelência em Gestão, 4, 2008, Niterói - Rio de Janeiro. Anais... Rio de Janeiro: CNEG, 2008. p. 2-14.

5. MACHADO FILHO, Cláudio Pinheiro. Responsabilidade social e governança: o debate e as implicações: responsabilidade social, instituições, governança e reputação. São Paulo: Ed. Pioneira Thomson Learning, 2006.

6. MINISTÉRIO DO MEIO AMBIENTE. A3P - Agenda Ambiental na Administração Pública; 5a Edição - Brasília-DF, 2009.

7. MOURA, Laysce Rocha de. Responsabilidade Social Corporativa: o papel social das organizações econômicas. In: AÑEZ, Miguel Eduardo Moreno; BATISTA-DOS-SANTOS, Ana Cristina; NASCIMENTO, Thiago Cavalcante; MEDEIROS, Paulo César; MACHADO, Hilka Vier. (Re)Pensando as Relações entre Organizações \& Sociedade: Excertos de Reflexão do I Encontro Franco Brasileiro de Responsabilidade Social: responsabilidade social, sustentabilidade, racionalidade e ética. Anais... Natal: EGRN, 2010. p. 113-127.

8. SCOTTO, Gabriela; CARVALHO, Isabel Cristina de Moura; GUIMARÃES, Leandro Belinaso Desenvolvimento Sustentável. 2. ed. Petrópolis, RJ: Ed. Vozes, 2007. 
9. VERGARA, Sylvia Constant. Projetos e relatórios de pesquisa em Administração. SÃO PAULO: Editora Atlas, 1998.

10. YIN, Robert K. Estudo de caso: Planejamento e métodos. Trad. Cristhian Matheus Herrera. 5a edição. Porto Alegre: Bookman, 2015. 